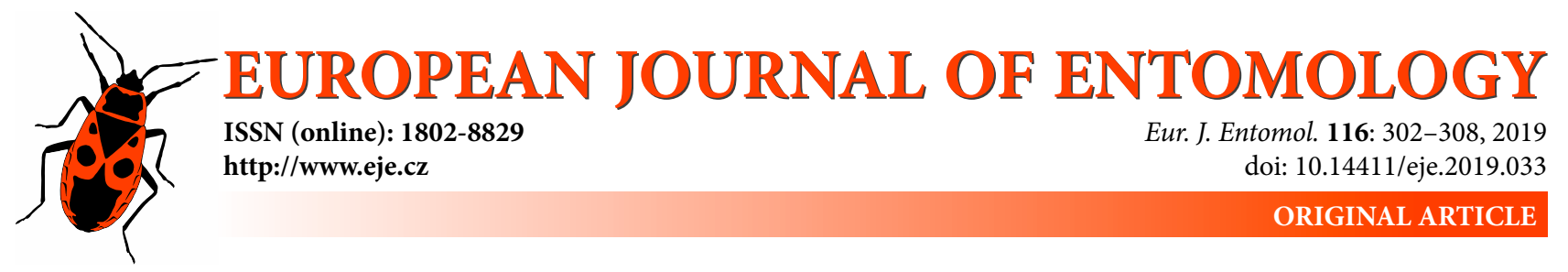

\title{
Cannibalism among same-aged nymphs of the omnivorous predator Dicyphus errans (Hemiptera: Miridae) is affected by food availability and nymphal density
}

\author{
Konstantina ARVANITI' ${ }^{1}$, Argyro FAnTINOU ${ }^{2}$ and Dionyssios PERDIKIS ${ }^{1}$ \\ ${ }^{1}$ Laboratory of Agricultural Zoology \& Entomology and ${ }^{2}$ Laboratory of Ecology \& Environmental Sciences, Agricultural University \\ of Athens, lera Odos 75, 118 55, Athens, Hellenic Republic; e-mails: konarvaniti@gmail.com, argyr@aua.gr, dperdikis@aua.gr
}

Key words. Hemiptera, Miridae, Dicyphus errans, adult weight, cannibalism, density, development, food availability, omnivorous predator

\begin{abstract}
Cannibalism, the act of eating an individual of the same species has been little studied in omnivorous insect predators. Dicyphus errans (Wolff) (Hemiptera: Miridae) is a generalist omnivorous predator that commonly occurs in tomato greenhouses and field crops in the Mediterranean basin. In this work cannibalism among same-aged neonate nymphs of $D$. errans was studied when 1, 2, 4, 8 or 16 individuals were placed in a Petri dish along with or without heterospecific prey. Although nymphs were unable to complete their development in the absence of prey they survived longer when there were initially 2 individuals per dish than in any other treatment including a single individual. This may indicate that cannibalism in this predator has positive effect on nymphal survival, which however was not the case at higher densities. The presence of heterospecific prey increased nymphal survival and individuals were as equally successful in completing their development as when kept singly. Developmental time in all the treatments was very similar. Adult weight of both females and males was significantly greater when a nymph was reared alone and similar in all the other treatments. The results indicate that cannibalism occurs among neonates of $D$. errans if heterospecific prey is scarce and has a negative effect on adult weight when heterospecific prey is abundant. This should be considered in studies on enhancing the biocontrol efficiency or mass rearing of this predator.
\end{abstract}

\section{INTRODUCTION}

Cannibalism, the process of killing and consuming a part or all of a conspecific occurs in a wide range of carnivorous as well as in phytophagous arthropods (Fox, 1975; Polis, 1981; Woodward \& Hildrew, 2002; Richardson et al., 2010; Booth et al., 2017). This behaviour may enhance fitness of cannibals in periods of food scarcity by providing them access to high quality nutrients, reducing competition or decreasing the risk of predation and/or parasitism (Fox, 1975; Polis, 1981; Gabriel, 1985; Van den Bosch et al., 1988; Agarwala \& Dixon, 1992; Elgar \& Crespi, 1992; Henson, 1997; Gagné et al., 2002; Michaud, 2003; Claessen et al., 2004; Booth et al., 2017). Nevertheless, cannibalism may incur costs, including the risk of injuries from conspecifics that fight back or the transmission of pathogens and parasites present in the victim attacked (Elgar \& Crespi, 1992).

Various biotic and abiotic factors affect the incidence of cannibalism in insect assemblages. The scarcity of alternative food is considered the most important factor promoting cannibalism (Fox, 1975; Polis, 1981; Agarwala \& Dixon, 1992; Currie et al., 1996; George, 2002; Schausberger, 2003). Population density and population structure of interacting conspecifics are also important drivers of cannibalistic behaviour resulting in (a) more cannibalism when the density of interacting conspecifics is high and (b) larger individuals being more effective cannibals than smaller ones (Fox, 1975; Polis, 1980, 1981; Dong \& Polis, 1992; Claessen et al., 2004; Reglero et al., 2011; Duan et al., 2013; Parsons et al., 2013). Cannibalism is also influenced by the strength of intraspecific competition, mating status, habitat structure and hunger level (Polis, 1981; Wise, 2006).

Apart from mortality, cannibalism may have adverse effects on life-history traits such as developmental rate or weight gain (Fox, 1975; Polis, 1980; Lima, 1998). Studies on phytophagous insects indicate that when immatures are abundant they grow slowly and are lighter as adults (Duan et al., 2013; Andow et al., 2015). The factors that affect the intensity of these trait-mediated effects of cannibalism and their implications at the population level are less well studied (Ruldof, 2007).

Omnivorous predatory insects are valuable biological control agents in tomato and other vegetable crops and are widely used commercially. Although interactions commonly occur among them such as those associated 
with intraguild predation (Lucas et al., 2009; Moreno et al., 2012), the cannibalistic behaviour of only a few species are documented (Tommasini et al., 2002; Laycock et al., 2006; Leon-Beck \& Coll, 2007). Hamdi et al. (2013) show that females and males of Macrolophus pygmaeus (Rambur) (Hemiptera: Miridae) eat their own first instar nymphs regardless of the availability of heterospecific prey. Adult females of Dicyphus hesperus Knight (Hemiptera: Miridae) attack and eat first and fourth instar nymphs and male conspecifics (Laycock et al., 2006). Similarly, adult females or $4^{\text {th }}$ instar nymphs of Dicyphus tamaninit Wagner (Hemiptera: Miridae) also eat their own $1^{\text {st }}$ instar nymphs (Castañé et al., 2002). Therefore, omnivores engage in size-related cannibalism.

Cannibalism has important consequences for the utilization of omnivorous predators in biological control. For example, cannibalism can be an impediment to the mass production of natural enemies (Riddick \& Wu, 2010; De Clercq et al., 2013). As omnivores are also released early in the cropping cycle, when heterospecific prey is usually scarce, cannibalism may greatly reduce their abundance and have a negative effect on their establishment (Calvo et al., 2012; Perdikis et al., 2015; Moerkens et al., 2017). In addition, as they are usually released into crops as adults their offspring can be abundant and, as a result, cannibalism is more likely to occur, which would adversely affect their establishment. In fact, the effect of cannibalism is dependent upon the timing of its occurrence, being more pronounced when it occurs in early life as it has important consequences for survival, development, body size and reproduction (Ghazy et al., 2016). However not much is known about cannibalism among same-aged neonate nymphs. Since one of the major risks of being a cannibal is being injured by the victim defending itself (Polis, 1981; Montserrat et al., 2006), the study of the cannibalism occurring between same-aged nymphs is challenging because they may both injure each other (Fox, 1975; Polis, 1980). Under these circumstances the benefits of being a cannibal or the factors affecting the intensity of cannibalism have to be assessed. Although such effects have important demographic and ecological effects on populations they are not well studied (Rudolf, 2007).

Dicyphus errans (Wolff) (Hemiptera: Miridae) is a generalist omnivorous predator that commonly occurs in tomato greenhouses and field crops in the Mediterranean basin. Its efficacy against whiteflies, aphids and the recently arrived devastating pest of tomatoes, Tuta absoluta (Meyrick) (Lepidoptera: Gelechiidae), is frequently reported (Lambion, 2011; Ingegno et al., 2013, 2017a, b, 2019). Its use to control aphids in sweet pepper greenhouse crops has been evaluated positively by Messelink et al. (2014). Dicyphus errans is a promising natural enemy, however, it may attack and consume conspecifics. However, to the best of our knowledge cannibalism has not yet been explored in this species.

In the present study we determined the incidence of cannibalism in groups of different numbers of same-aged neonate nymphs of the omnivore $D$. errans in (a) the absence and (b) presence of heterospecific prey. Our hypotheses were that a) the absence of heterospecific prey would result in starvation, facilitate cannibalism and result in a higher survivorship of the cannibals and their achieving a greater size (Gabriel, 1985; Van den Bosch et al., 1988; Henson, 1997), (b) the presence of heterospecific prey would result in a lower incidence of cannibalism and (c) an abundance of conspecifics would result in a greater incidence of cannibalism.

\section{MATERIALS AND METHODS}

\section{Biological material}

Rearing of $D$. errans was initiated from adults and late instar nymphs collected from Solanum nigrum L. (Solanaceae) at Kato Samiko, Ilia (W. Peloponnese, 37 $54^{\prime} 41.05^{\prime \prime} \mathrm{N}, 21^{\circ} 59^{\prime} 92.57^{\prime \prime} \mathrm{E}$, GPS). Insects were reared on potted tobacco plants (cv. Basmas) and provided ad libitum with Ephestia kuehniella Zeller (Lepidoptera: Pyralidae) eggs and dried Artemia sp. cysts (Crustaceae) (Entofood, Koppert B.V., The Netherlands) as food. Cultures of plants and $D$. errans were maintained in wood-framed entomological cages (length $80 \mathrm{~cm} \times$ width $80 \mathrm{~cm} \times$ height $70 \mathrm{~cm}$ ) and kept in an insectary at $25 \pm 1{ }^{\circ} \mathrm{C}, 65 \pm 5 \% \mathrm{RH}$ and a photoperiod of $16 \mathrm{~L}: 8 \mathrm{D}$. Tomato leaves used in experiments were collected from 2-month old uninfested plants (cv. Elpida, Spirou House of Agriculture, Athens, Greece) kept under the above conditions. Both tobacco and tomato plants were grown without applying pesticides.

\section{Experimental design}

The experimental set-up consisted of plastic Petri dishes (Ø 9 $\mathrm{cm}, 1.5 \mathrm{~cm}$ height) with a mesh-covered hole in the lid $(\varnothing 3 \mathrm{~cm})$ to reduce the level of humidity. A leaflet of a tomato plant was placed, abaxial surface up, on a layer of water-moistened cotton on the bottom of each Petri dish. The petiole of the tomato leaflet was wrapped in absorbent cotton, which was soaked with water daily. The leaflet was replaced with a new one every 2 days. In all experiments neonate nymphs (less than 24-h old) of D. errans were used. These were collected from individually caged tobacco plants with 6-8 fully expanded leaves. Ten adults of D. errans ( 5 females and 5 males) were introduced into each cage and they laid eggs in the stem of the plant. On the leaves of each plant $E$. kuehniella eggs and cysts of Artemia sp. were added ad libitum as prey for the adults. The plants in the cages were inspected every $24 \mathrm{~h}$ and the freshly emerged nymphs were randomly assigned to each treatment. The cages were kept in a growth chamber at $25 \pm 1{ }^{\circ} \mathrm{C}, 65 \pm 5 \% \mathrm{RH}$ and a photoperiod of $16 \mathrm{~L}: 8 \mathrm{D}$.

Depending on the treatment, initial nymphal densities were 2, 4,8 or 16 neonate nymphs per Petri dish. A dish with a single nymph was used as a control. The treatments were either the presence or absence of heterospecific prey on the tomato leaflet. As prey E. kuehniella eggs and cysts of Artemia sp. were provided ad libitum dispersed evenly on the leaflet. Petri dishes were firmly sealed with parafilm. Each group of nymphs in a dish was considered a replicate. In each treatment 15 dishes (replicates) were used. In all cases, the survival of each nymph was assessed every day till death or adult emergence. Dead and consumed nymphs were recorded as cannibalized. The newly emerged adults were anaesthetized in a $4^{\circ} \mathrm{C}$ freezer, weighed using a Kern 770 electronic balance (Kern and Sohn GmbH, Balingen, Germany) with a precision of $0.1 \mathrm{mg}$ and their sex determined. All experiments were conducted at $25 \pm 1{ }^{\circ} \mathrm{C}, 65 \pm 5 \% \mathrm{RH}$ and $16 \mathrm{~L}: 8 \mathrm{D}$ photoperiod. 


\section{Statistical analyses}

In the absence of heterospecific prey the survival curves were obtained using Kaplan-Meier estimators in the software Sigma Plot 12.0 (Systat Software Inc., 2011). In the treatment in which the nymphs developed in groups of 2 , the survival curves of the nymphs killed and that of the cannibals, and that of those that killed each other (i.e. both were found dead on the same day) were compared with each other and with that of the nymphs kept singly. The curves were compared using the Log-Rank procedure. The regression between the length of survival of the nymphs that were killed and that of their cannibals was also calculated.

In the presence of heterospecific prey the percentage of nymphs that completed development in the different treatments were compared using Chi-square tests. The length of development was not affected by their $\operatorname{sex}(\mathrm{F}=1.24, \mathrm{df}=1,374, \mathrm{P}>0.25)$ so the data were pooled and analyzed using one-way ANOVA with the factor, the "treatment, nymphal density", after log-transformation. Studying the interactions in more depth, the length of survival of the last individual surviving in a dish, was used as a surrogate for the benefits of cannibalism. These data were analyzed using oneway ANOVA with the factor the "treatment, nymphal density", after log-transformation. The adult weights were analyzed using a two-way ANOVA after square root transformation. In this case, the factors were "treatment, nymphal density" and "sex of the emerged adult". Means were compared using the Tukey-Kramer HSD test. Analyses were conducted using the statistical package JMP (SAS Institute, 2016).

\section{RESULTS}

\section{Absence of heterospecific prey}

In the absence of heterospecific prey the nymphs were unable to complete development to the adult stage. Their survival curves were significantly different in the different treatments $(\mathrm{H}=85.02, \mathrm{df}=4, \mathrm{P}<0.001)$ (Fig. 1). Nymphs that were reared at 2 per dish survived significantly longer than solitary nymphs $(\mathrm{H}=5.78$, df $=1, \mathrm{P}=0.016)$. The length of survival of individually reared nymphs was significantly longer than that of those in groups of 4,8 or $16(\mathrm{H}=19.22, \mathrm{df}=1, \mathrm{P}<0.001, \mathrm{H}=18.95, \mathrm{df}=1, \mathrm{P}<$ 0.001 and $\mathrm{H}=20.45$, df $=1, \mathrm{P}<0.001$, at each density, respectively). There was no significant difference in survival curves of the nymphs reared in groups of 4,8 and 16 individuals per dish.

The length of survival of the last surviving individual of a group in a dish was significantly longer when 2 indi-

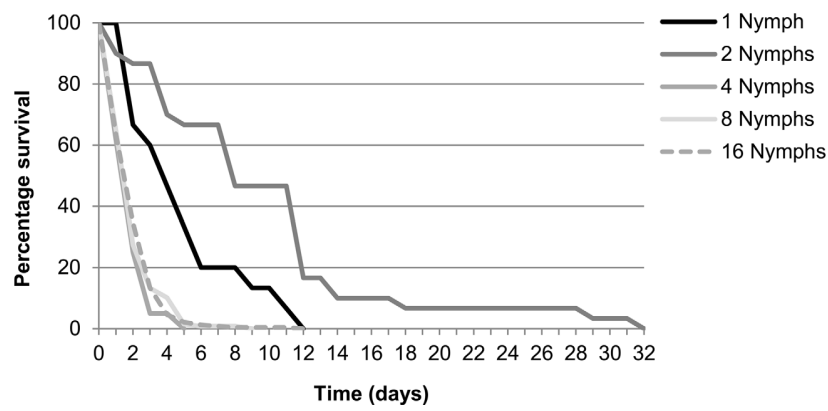

Fig. 1. Percentage survival over time of neonate nymphs of Dicyphus errans that were kept individually or in groups of 2, 4, 8 or 16 nymphs, on a tomato leaflet in a Petri dish, without heterospecific prey, at $25 \pm 1^{\circ} \mathrm{C}, 65 \pm 5 \% \mathrm{RH}$ and a photoperiod of $16 \mathrm{~L}: 8 \mathrm{D}$.

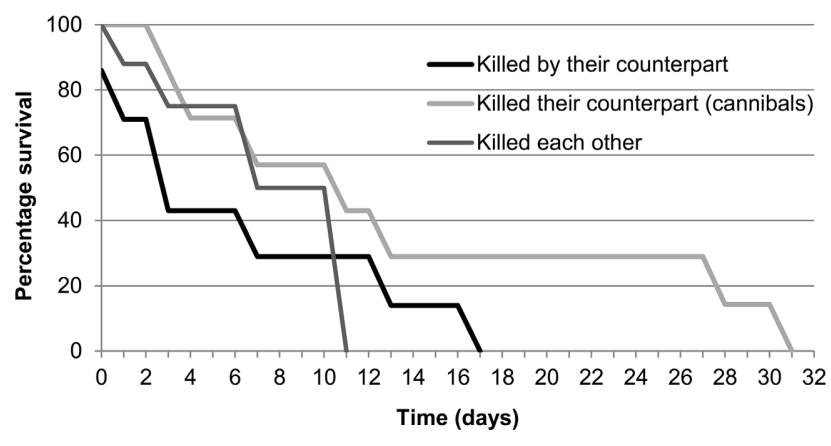

Fig. 2. Percentage survival over time of neonate nymphs of Dicyphus errans that were kept in groups of 2: (a) of the one killed, (b) the cannibal and (c) of both when they were found dead on the same day. The nymphs were kept on a tomato leaflet in a Petri dish, without heterospecific prey, at $25 \pm 1^{\circ} \mathrm{C}, 65 \pm 5 \% \mathrm{RH}$ and a photoperiod of $16 \mathrm{~L}: 8 \mathrm{D}$.

viduals were reared together and significantly shorter than that recorded in the treatments with 4,8 and 16 individuals $(7.43 \pm 2.23,1.75 \pm 0.35,2.00 \pm 0.71$ and $1.71 \pm 0.47$ days (mean \pm s.e.), respectively, $\mathrm{F}=5.71$, $\mathrm{df}=3,26, \mathrm{P}=0.004$ ). Furthermore, in the treatment with 2 individuals per dish, the cannibalized nymph in 7 dishes survived for on average $6.28 \pm 2.14$ days from the start of the experiment. In the rest of dishes in the above treatment, both nymphs were found dead on the same day and this occurred on average after $7.31 \pm 1.85$ days from the start of the experiment. The respective survival curves of the nymphs killed by the cannibal, the cannibal and those that killed each other are shown in Fig. 2. The survival curve of the cannibals differed significantly from that of the nymphs that developed singly $(\mathrm{H}=5.63$, $\mathrm{df}=1, \mathrm{P}=0.0176)$. The regression between the length of survival of nymphs that were killed and that of the combined length of survival of the respective cannibals has a significantly positive slope $(\mathrm{F}=20.85, \mathrm{df}=$ 5, $\mathrm{P}=0.006, \mathrm{R}^{2} \mathrm{adj}=0.76$ ) (Fig. 3).

\section{Presence of heterospecific prey}

\section{Survival}

In the presence of heterospecific prey, most of the nymphs completed their development $(100 \%, 80 \pm 7.8 \%$, $100 \%, 96 \pm 1.5 \%$ and $84 \pm 3.2 \%$, respectively, for $1,2,4$,

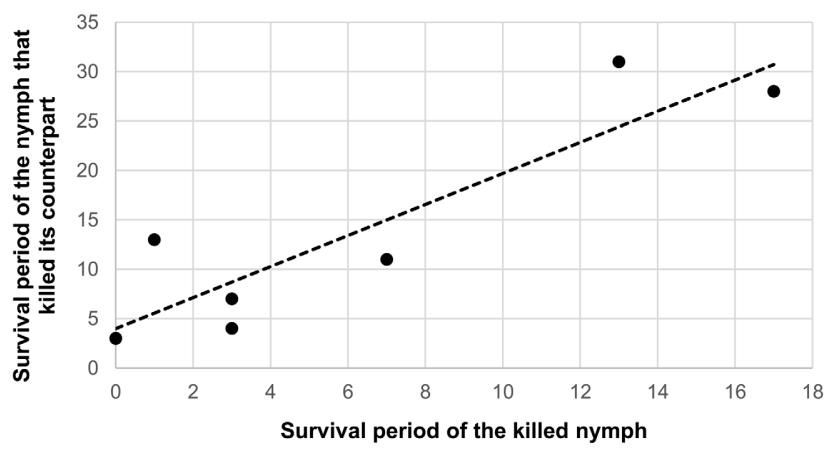

Fig. 3. Regression between the period of survival (days) of nymphs of Dicyphus errans that were killed by the other nymph and that of the period of survival of the cannibal, when kept in groups of 2 on a tomato leaflet in a Petri dish, without heterospecific prey, at $25 \pm$ $1^{\circ} \mathrm{C}, 65 \pm 5 \% \mathrm{RH}$ and a $16 \mathrm{~L}: 8 \mathrm{D}$ photoperiod. 


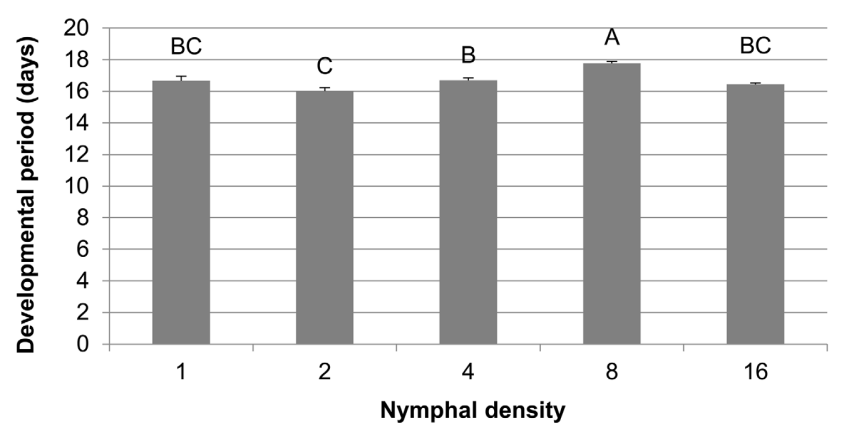

Fig. 4. Histogram of the durations of development (days) (mean \pm s.e.) of nymphs of Dicyphus errans kept individually or in groups of $2,4,8$ or 16 nymphs, on a tomato leaflet in a Petri dish with heterospecific prey, at $25 \pm 1^{\circ} \mathrm{C}, 65 \pm 5 \% \mathrm{RH}$ and a photoperiod of $16 \mathrm{~L}: 8 \mathrm{D}$. Columns topped by the same letter are not significantly different $(a=0.05)$.

8 and 16 individuals per dish). Percentage of adults that emerged did not differ significantly in the different treatments $\left(\chi^{2}=15.02, \mathrm{df}=4, \mathrm{P}=0.09\right)$.

\section{Duration of development}

The duration of development was significantly affected by the "treatment, nymphal density" $(\mathrm{F}=23.34, \mathrm{df}=4,371$, $\mathrm{P}<0.001$ ) (Fig. 4). A significantly longer duration of development was recorded when there was 8 nymphs per dish than in the other treatments in which a significantly longer duration of development was recorded in the dishes with 4 compared to 2 individuals per dish.

\section{Adult weight}

The number of nymphs and sex significantly affected adult weight $(\mathrm{F}=30.95$, df $=4,366, \mathrm{P}<0.001$, and $\mathrm{F}=$ 672.11 , df $=1,366, \mathrm{P}<0.001$, respectively) whereas the interaction between these two factors was not significant $(\mathrm{F}=2.38, \mathrm{df}=4,366, \mathrm{P}=0.051)$ (Fig. 5). Both male and female adults were significantly heavier when the nymphs

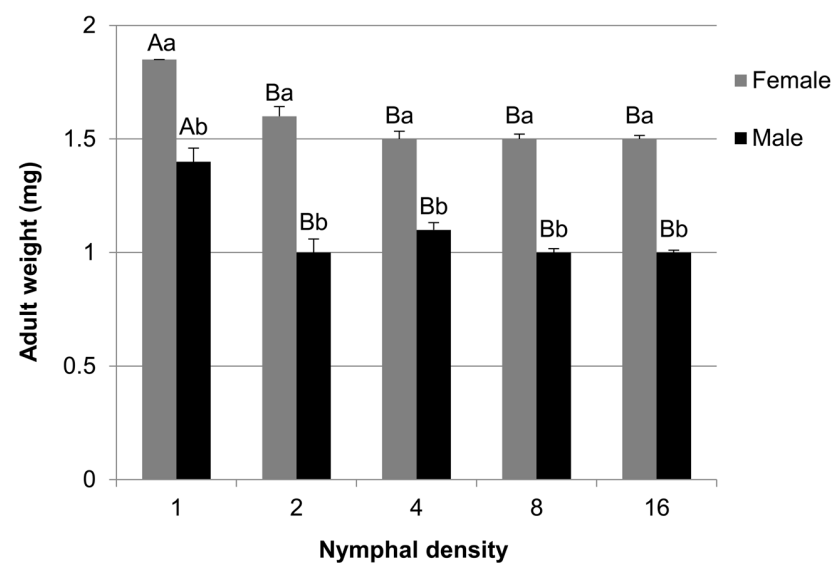

Fig. 5. Histogram of the adult female and male weights (mg) (mean \pm s.e.) of Dicyphus errans nymphs which were kept individually (a single nymph) or in groups of $2,4,8$ or 16 nymphs, on tomato leaflet in a Petri dish with heterospecific prey, at $25 \pm 1{ }^{\circ} \mathrm{C}, 65 \pm$ $5 \% \mathrm{RH}$ and a photoperiod of $16 \mathrm{~L}: 8 \mathrm{D}$. Columns for females and males, respectively, topped by the same capital letter are not significantly different among treatments; different lower case letters indicate significant differences between females and males within each treatemnt $(a=0.05)$. were reared individually rather than in groups. The weight of females and males did not differ significantly when 2,4 , 8 and 16 nymphs were reared per dish, but the females in each treatment were significantly heavier than the males.

\section{DISCUSSION}

Studies on intraspecific interactions in arthropods have revealed that density and food availability are among the important factors affecting the occurrence of cannibalism (Fox, 1975; Polis, 1981). In zoophytophagous predators it is assumed that the incidence of cannibalism is determined by the availability of alternative prey or plant resources (Laycock et al., 2006; Leon-Beck \& Coll, 2007). In the present study we show that the incidence of cannibalism in the omnivore, D. errans is correlated with the availability of heterospecific prey.

Overall, in the absence of the heterospecific prey nymphs reared in isolation were not able to complete their development. There was a significant increase, however, in the period for which the nymphs survived, when two same aged individuals were enclosed together. Furthermore, the mean time for which the last surviving nymph survived was substantially increased and comparable to that of singly reared individuals. In addition, the survival analysis showed that the cannibals survived for significantly longer than nymphs reared singly. These results demonstrate that feeding on a conspecific enhanced nymphal survival in this predator. Previous studies report that conspecifics are a similar or even better food source than heterospecific prey (Agarwala \& Dixon, 1992; Buitenhuis et al., 2010). This would seem to be supported by the regression analysis, which indicates that the consumption of a nymph in a later stage of development resulted in the cannibal surviving for longer. However, the last surviving nymph in a group of initially more than 2 individuals per dish did not benefit from the presence of more conspecifics in terms of the length of time it survived, even though it could feed on the dead individuals. Thus, it is likely that in the high density treatments the aggressive behaviour of conspecifics results in lethal injuries to both cannibals and victims. Moreover, the equivalent skills in attack or defense of same-aged nymphs increase the probability of being injured or killed during contests. In the treatment with 2 individuals per dish, in half of the replicates the interactions were lethal for both nymphs. More specifically, one of the nymphs died on average after 6.28 days and both were dead after 7.31 days from the start of the experiment. These periods are approximately the same length of time for which the nymphs survived when kept singly on a leaf without prey (5.06 days), indicating that at about that time the hunger level of the individuals induced them to attack conspecifics. Therefore, cannibalism is adaptive in D. errans and occurs when individuals are starving.

Results for the closely related species, D. hesperus, indicate that on average 0.53 and 0.18 nymphs are killed in 24 $\mathrm{h}$ when an adult female is kept together with 12 first- or 12 fourth-instar nymphs ( $<24 \mathrm{~h}$ old) in $60-\mathrm{ml}$ plastic arenas (Laycock et al., 2006). According to Hamdi et al. (2013) a 
female of $M$. pygmaeus kept with 5 first instar nymphs in the presence of water and a leaf and absence of lepidopteran eggs, consumes $59 \%$ of the nymphs in $48 \mathrm{~h}$. Although the experimental conditions in these studies differ in several ways and thus the results are not directly comparable with those of our research, our results indicate that cannibalism in D. errans is more marked because the first instar nymphs of $D$. errans were killed within a short period of time (within $48 \mathrm{~h}, 75 \%$ and $70 \%$ of the nymphs in the treatments with 4 and 8 individuals per dish, were killed). Therefore, neonates of $D$. errans readily resort to cannibalism and feed upon conspecifics. Thus, when studying the incidence of cannibalism in groups of individuals, as in the studies of Laycock et al. (2006) and Hamdi et al. (2013) cannibalism among neonates should be considered. In this context, the percentage cannibalism of three $1^{\text {st }}$ instar nymphs of $D$. tamaninii developing together without prey for seven days is 30\% (Castañé et al., 2002). Therefore, regarding the use $D$. errans in biological control, cannibalism among neonates when prey is scarce could adversely affect their establishment on a tomato crop.

In the presence of heterospecific prey the incidence of cannibalism was much reduced and a high percentage of the nymphs reached adulthood in all the treatments, which is similar to that recorded for single individuals $(100 \%)$. This agrees with the expectation that cannibalism is inversely related to food supply (Agarwala \& Dixon, 1992; Currie et al., 1996; George, 2002) and is in accordance with results for other mirid predators (Laycock et al., 2006; Hamdi et al., 2013).

The duration of development of the nymphs when provided with heterospecific prey varied very slightly. It was significantly longer in the treatment with 8 nymphs, which indicates a more adverse effect of intermediate numbers of nymphs on development. An adverse effect of cannibalism is slower development (Lima, 1998; Chapman et al., 1999; Duan et al., 2013). It is likely that when there are few nymphs (i.e. 2 nymphs per dish) foraging they are less likely to encounter and attack a conspecific nymph (Andow et al., 2015). As the numbers increase the incidence of encounters is likely to increase resulting in an increase in aggressive behaviour or decrease in foraging for prey (Ferris \& Rudolf, 2007). As a result, nymphs might decrease or cease feeding and as a consequence take longer to develop as recorded in the treatments with 8 and 4 individuals. However, in the treatment with 16 individuals per dish, the frequency of contacts with other nymphs is likely to be high and as a consequence they reduced the time to complete their development in order to reduce the risk of injury. Presumably there might be a density threshold below which nymphs can easily find food and above which they are subject to an increased risk of injury, conditions which make it advantageous to increase their rate of development. However at moderate densities close to the threshold, nymphs might also experience more intense competition for resources, a fact that finally might lead to longer developmental period as a response to increased crowding. This threshold is likely to depend on the size of the arena or habitat complexity. This hypothesis, however, needs to be tested in future studies.

Interestingly, the weight of adults that developed from nymphs kept in groups was always significantly lower than when kept singly and there were no significant differences in the weights of the adults developing from nymphs kept in groups. The adverse effect on adult weight may be attributed to the energy cost of the interactions between nymphs or decreased food consumption due to competition (Chapman et al., 1999). Studies on the herbivores Spodoptera frugiperda (Smith) (Lepidoptera: Noctuidae) (Andow et al., 2015) and Agrilus planipennis Fairmaire (Coleoptera: Buprestidae) (Duan et al., 2013) indicate that the adults that develop from immatures that were kept crowded during their development are lighter. Furthermore, according to Duan et al. (2013) the adult weight of A. planipennis linearly decreases with increase in conspecific density showing an increasing magnitude of the adverse effects of cannibalism on adult weight. In comparison with $D$. errans the fact that the weight of the adults was not dependent on density between 2 and 16 individuals per dish, together with the lower mortality, are likely to indicate that cannibalism is not important when heterospecific prey is abundant. The low incidence of cannibalism in D. errans when prey is abundant implies the mass rearing of this predator at high densities is possible, provided it is supplied with an abundance of heterospecific food.

Our results are the first on cannibalism in D. errans. The adverse effects of cannibalism were much stronger in the absence of heterospecific prey, however, there was a greater increase in the period for which nymphs survived when there were 2 individuals in a dish than when there were more than two per dish. Even though, cannibalism was not recorded in the presence of heterospecific prey, adult weight was inversely dependent on the numbers of nymphs in a dish. These results indicate that cannibalism is adaptive in D. errans. The role of cannibalism in the population dynamics and mass rearing of $D$. errans, and its use in biological control needs further study.

DISCLOSURE. The authors declare no conflict of interest.

\section{REFERENCES}

Agarwala B.K. \& Dixon A.F.G. 1992: Laboratory study of cannibalism and interspecific predation in ladybirds. - Ecol. Entomol. 17: 303-309.

Andow D.A., Farias J.R., Horiskoshi R.J., Bernard D., NasciMENTo A.R.B. \& Омото C. 2015: Dynamics of cannibalism in equal-aged cohorts of Spodoptera frugiperda. - Ecol. Entomol. 40: 229-236.

Booth E., Alyokhin A. \& Pinatti S. 2017: Adult cannibalism in an oligophagous herbivore, the Colorado potato beetle. - Insect Sci. 24: 295-302.

Buitenhuis R., Shipp L. \& Scott-Dupree C. 2010: Intra-guild vs extra-guild prey: Effect on predator fitness and preference of Amblyseius swirskii (Athias-Henriot) and Neoseiulus cucumeris (Oudemans) (Acari: Phytoseiidae). - Bull. Entomol. Res. 100: $167-173$.

Calvo F.J., Lorente M.J., Stansly P.A. \& Belda J.E. 2012: Preplant release of Nesidiocoris tenuis and supplementary tactics 
for control of Tuta absoluta and Bemisa tabaci in greenhouse tomato. - Entomol. Exp. Appl. 143: 111-119.

Castañé C., Iriarte J. \& Lucas E. 2002: Comparison of prey consumption by Dicyphus tamaninii reared conventionally, and on a meat-based diet. - BioControl 47: 657-666.

Chapman J.W., Williams T., Escribano A., Caballero P., Cave R.D. \& Goulson D. 1999: Age-related cannibalism and horizontal transmission of a nuclear polyhedrosis virus in larval Spodoptera frugiperda. - Ecol. Entomol. 24: 268-275.

Claessen D., De Roos A.M. \& Persson L. 2004: Population dynamic theory of size-dependent cannibalism. - Proc. R. Soc. Lond. (B) 271: 333-340.

Currie C.R., Spence J.R. \& Niemelä J. 1996: Competition, cannibalism, and intraguild predation among ground beetles $(\mathrm{Co}-$ leoptera: Carabidae): A laboratory study. - Coleopt. Bull. 50: 135-148.

De Clercq P., Coudron T.A. \& Riddick E.W. 2013: Production of heteropteran predators. In Morales-Ramos J.A., Rojas M.G. \& Shapiro-Ilan D.I. (eds): Mass Production of Beneficial Organisms: Invertebrates and Entomopathogens. Academic Press, London, pp. 57-100.

Dong Q. \& Polis G.A. 1992: The dynamics of cannibalistic populations: A foraging perspective. In Elgar M.A. \& Crespi B.J. (eds): Cannibalism: Ecology and Evolution among Diverse Taxa. Oxford Science Publications, Oxford, pp. 13-37.

Duan J.J., Larson K., Watt T., Gould J. \& Lelito J.P. 2013: Effects of host plant and larval density on intraspecific competition in larvae of the Emerald Ash Borer (Coleoptera: Buprestidae). - Environ. Entomol. 42: 1193-1200.

Elgar M.A. \& Crespi B.J. 1992: Cannibalism: Ecology and Evolution among Diverse Taxa. Oxford University Press, Oxford, viii $+361 \mathrm{pp}$.

FERRIS G. \& RUdOlF V. 2007: Responses of larval dragonflies to conspecific and heterospecific predator cues. - Ecol. Entomol. 32: 283-288.

Fox L.R. 1975: Cannibalism in natural-populations. - Annu. Rev. Ecol. Evol. Syst. 6: 87-106.

GABRIEL W. 1985: Overcoming food limitation by cannibalism: a model study of cyclopoid copepods. - Arch. Hydrobiol. 21: 373-381.

Gagné I., Coderre D. \& Mauffette Y. 2002: Egg cannibalism by Coleomegilla maculata lengi neonates: Preference even in the presence of essential prey. - Ecol. Entomol. 27: 285-291.

George P.J.E. 2002: Effect of starvation and density on the nymphal cannibalism of Rhynocoris fuscipes Fab. (Heteroptera: Reduviidae). - Entomon 27: 215-218.

Ghazy N.A., Osakabe M., Negm M.W., Schausberger P., Gotoh T. \& Amano H. 2016: Phytoseiid mites under environmental stress. - Biol. Contr. 96: 120-134.

Hamdi F., Chadoeuf J., Chermiti B. \& Bonato O. 2013: Evidence of cannibalism in Macrolophus pygmaeus, a natural enemy of whiteflies. - J. Insect Behav. 26: 614-621.

Henson S.M. 1997: Cannibalism can be beneficial even when its mean yield is less than one. - Theor. Popul. Biol. 51: 109-117.

Ingegno B.L., Ferracini C., Gallinotti D., Alma A. \& Tavella L. 2013: Evaluation of the effectiveness of Dicyphus errans (Wolff) as predator of Tuta absoluta (Meyrick). - Biol. Contr. 67: 246-252.

Ingegno B.L., Bodino N., Leman A., Messelink G.J. \& Tavella L. 2017b: Predatory efficacy of Dicyphus errans on different prey. - Acta Horticult. 1164: 425-430.

Ingegno B.L., Candian V., Psomadelis I., Bodino N. \& Tavella L. 2017a: The potential of host plants for biological control of Tuta absoluta by the predator Dicyphus errans. - Bull. Entomol. Res. 107: 340-348.
Ingegno B.L., Messelink G.J., Bodino N., Iliadou A., Driss L., Woelke J.B., Leman A. \& Tavella L. 2019: Functional response of the mirid predators Dicyphus bolivari and Dicyphus errans and their efficacy as biological control agents of Tuta absoluta on tomato. - J. Pest Sci. 92: 1457-1466.

LAmbion J. 2011: Functional biodiversity in Southern France: A method to enhance predatory mirid bug populations. - Acta Hortic. 915: 165-170.

Laycock A., Camm E., Van Laerhoven S. \& Gillespie D. 2006 : Cannibalism in a zoophytophagous omnivore is mediated by prey availability and plant substrate. - J. Insect Behav. 19: 219-229.

Leon-Beck M. \& Coll M. 2007: Plant and prey comsumption cause a similar reduction in cannibalism by an omnivorous bug. - J. Insect Behav. 20: 67-76.

Lima S.L. 1998: Nonlethal effects in the ecology of predator-prey interactions. - Bioscience 48: 25-34.

Lucas É., Fréchette B. \& Alomar O. 2009: Resource quality, resource availability, and intraguild predation among omnivorous mirids. - Biocontr. Sci. Technol. 19: 555-572.

Messelink G.J., Bennison J., Alomar O., Ingegno B.L., Tavella L., Shipp L., Palevsky E. \& Wäckers F.L. 2014: Approaches to conserving natural enemy populations in greenhouse crops: current methods and future prospects. - BioControl 59: 377 393.

MichAUD J.P. 2003: A comparative study of larval cannibalism in three species of ladybird. - Ecol. Entomol. 28: 92-101.

Moerkens R., Berckmoes E., Van Damme V., Wittemans L., Tirry L., Casteels H., De Clerce P. \& De Vis R. 2017: Inoculative release strategies of Macrolophus pygmaeus Rambur (Hemiptera: Miridae) in tomato crops: population dynamics and dispersal. - J. Plant Dis. Protect. 124: 295-303.

Montserrat M., Janssen A., Magalhaes S. \& Sabelis M.W. 2006: To be an intraguild predator or cannibal: is prey quality decisive? - Ecol. Entomol. 31: 430-436.

Moreno-Ripoll R., Agustí N., Berruezo R. \& Gabarra R. 2012: Conspecific and heterospecific interactions between two omnivorous predators on tomato. - Biol. Contr. 62: 189-196.

Parsons W., Zhong W. \& Rudolf V.H.W. 2013: Mating status and kin recognition influence the strength of cannibalism. - Anim. Behav. 85: 365-369.

Perdikis D.Ch., Arvaniti K., Paraskevopoulos A. \& Grigoriou A. 2015: Pre-plant release enhanced the earlier establishment of Nesidiocoris tenuis in open field tomato. - Entomol. Hell. 24: $11-21$.

Polis G.A. 1980: The effect of cannibalism on the demography and activity of a natural population of desert scorpions. Behav. Ecol. Sociobiol. 7: 25-35.

Polis G.A. 1981: The evolution and dynamics of intraspecific predation. - Annu. Rev. Ecol. Evol. Syst. 12: 225-251.

Reglero P., Urtizberea A., Torres A.P., Alemany F. \& Fiksen O. 2011: Cannibalism among size classes of larvae may be a substantial mortality component in tuna. - Mar. Ecol. Prog. Ser. 433: 205-219.

Richardson M.L., Mitchell R.F., Reagel P.F. \& Hanks L.M. 2010: Causes and consequences of cannibalism in noncarnivorous insects. - Annu. Rev. Entomol. 55: 39-53.

Riddick E.W. \& WU Z. 2010: Potential long-term storage of the predatory mite Phytoseiulus persimilis. - BioControl 55: 639-644.

Rudolf V.H.W. 2007: Consequences of stage-structured predators: cannibalism, behavioral effects and trophic cascades. Ecology 88: 2991-3003.

SAS INSTITUTE 2016: JMP Version 14.0.0. SAS Institute Inc. 
Schausberger P. 2003: Cannibalism among phytoseiid mites: a review. - Exp. Appl. Acarol. 29: 173-191.

Systat Software Inc. 2011: SigmaPlot for Windows. Version 12.00. San Jose, CA.

Tommasini M.G., Burgio G., Mazzoni F. \& Maini S. 2002: On intra-guild predation and cannibalism in Orius insidiosus and Orius laevigatus (Rhynchota: Anthochoridae): Laboratory experiments. - Bull. Insectol. 55: 49-54.
Van den Bosch F., De Roos A.M. \& Gabriel W. 1988: Cannibalism as a life boat mechanism. - J. Math. Biol. 26: 619-633.

Wise D.H. 2006: Cannibalism, food limitation, intraspecific competition, and the regulation of spider populations. - Annu. Rev. Entomol. 51: 441-465.

WoOdWARD G. \& Hildrew A.G. 2002: Body-size determinants of niche overlap and intraguild predation within a complex food web. - J. Anim. Ecol. 71: 1063-1074.

Received May 22, 2019; revised and accepted August 22, 2019 Published online September 19, 2019 